\title{
A Case of Alpha-Fetoprotein-Producing Adenocarcinoma of the Esophagogastric Junction in which Long-Term Survival Was Achieved by Means of Individualized Multidisciplinary Therapy
}

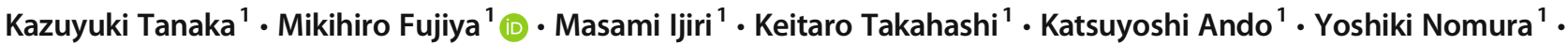 \\ Nobuhiro Ueno ${ }^{1}$. Shin Kashima ${ }^{1} \cdot$ Takuma Goto $^{1}$ - Junpei Sasajima ${ }^{1} \cdot$ Takahiro Ito $^{2} \cdot$ Kentaro Moriichi $^{1}$. \\ Yusuke Mizukami ${ }^{1} \cdot$ Hiroki Tanabe $^{3} \cdot$ Toshikatsu Okumura $^{1}$
}

Published online: 19 February 2018

(C) The Author(s) 2018. This article is an open access publication

\section{Introduction}

Carcinoma of the esophagogastric junction (EGJ) is a type of upper digestive cancer that occurs within $2 \mathrm{~cm}$ above or below the EGJ regardless of the histological type. Most cases of carcinoma of the EGJ are detected at an advanced stage and thus show a poor prognosis $[1,2]$. The most frequent sites of lymph node metastasis in carcinoma of the EGJ differ from carcinomas in other portions of the gastric tract and esophageal cancers, and a thoracic approach is sometimes taken during surgery. For this reason, unusual procedures (including lymph node dissection) and reconstruction methods are frequently required [3-6]. To date, the therapeutic strategy has not been fully established for carcinoma of the EGJ.

Alpha-fetoprotein (AFP) is a useful tumor marker for primary hepatocellular carcinoma and yolk sac tumor [7]. Although AFP-producing cancer develops in the stomach, such tumors rarely developed at the EGJ. AFP-producing carcinoma is thought to have a high potential for metastasis, particularly liver metastasis [8-11] and thus show a poor prognosis $[10,12]$. We herein report a case of AFP-producing carcinoma of the EGJ in which long-term survival was achieved through multidisciplinary therapy.

Mikihiro Fujiya

fjym@asahikawa-med.ac.jp

1 Division of Gastroenterology and Hematology/Oncology, Department of Medicine, Asahikawa Medical University, 2-1 Midorigaoka-higashi, Asahikawa, Hokkaido 078-8510, Japan

2 Inflammatory Bowel Disease Center, Sapporo Higashi Tokushukai Hospital, Sapporo, Japan

3 Department of Gastroenterology, Asahikawa Kousei Hospital, Asahikawa, Japan

\section{Case Report}

A 75-year-old man with hypertension, diabetes, and dyslipidemia underwent esophagogastroduodenoscopy to investigate the cause of a high CEA value and dysphagia in December 2010. An ulcerative circular tumor was detected at the EGJ (Fig. 1). Tubular adenocarcinoma cells were histologically detected in a tumor biopsy specimen. A laboratory analysis revealed mild anemia (hemoglobin $12.0 \mathrm{~g} / \mathrm{dL}$ ), renal dysfunction (creatinine $1.39 \mathrm{mg} / \mathrm{dL}$, cystatin C $1.35 \mathrm{mg} / \mathrm{L}$ ), and a high level of HbAlc (7.1\%). An analysis of the patient's serum revealed the following findings: squamous cell carcinoma (SCC), $3.4 \mathrm{ng} / \mathrm{mL}$ (normal range, $<1.5 \mathrm{ng} / \mathrm{mL}$ ); carcinoembryonic antigen (CEA), $50.0 \mathrm{ng} / \mathrm{mL}$ (normal range, $<5 \mathrm{ng} / \mathrm{mL}$ ); and carbohydrate 19-9 antigen (CA19-9), $1 \mathrm{U} / \mathrm{mL}$ (normal range, $<37 \mathrm{U} / \mathrm{mL}$ ). An upper gastrointestinal series, which was performed for further confirmation, showed an irregular filling defect at the EGJ. The oral side of the lesion spread to the lower third of the esophagus; the stenosis was $3 \mathrm{~cm}$ in length. Computed tomography (CT) revealed wall thickening at the EGJ, multiple mediastinal and abdominal lymph node metastases, and multiple liver metastases in both lobes (Fig. 1). Magnetic resonance imaging (MRI) confirmed that the lesions were multiple liver metastases. Because the patient's esophageal stenosis was symptomatic, total gastrectomy and lower esophagus resection with D2 lymph node dissection were performed. A histopathological examination showed the local production of AFP in moderately to poorly differentiated adenocarcinoma (Fig. 1). Due to the presence of the AFP-producing tumor, we checked the AFP level after surgery. At $568 \mathrm{ng} / \mathrm{mL}$ (normal range, $<5 \mathrm{ng} / \mathrm{mL}$ ), the AFP level was elevated. First line chemotherapy with S-1 (100 mg/ body on days 1 to 14) and docetaxel (50 mg/body on days 1 and 15) was administered in February 2011. While S-1 + cis- 
Fig. 1 Endoscopic and computed tomography (CT) findings. a Esophagogastroduodenoscopy revealed a $3 \mathrm{~cm}$-tumor with ulceration at the esophagogastric junction (EGJ). b Computed tomography showed multiple metastases in the lymph nodes and liver. c A histological examination revealed moderately to poorly differentiated adenocarcinoma with focal alphafetoprotein-positive cells in the EGJ
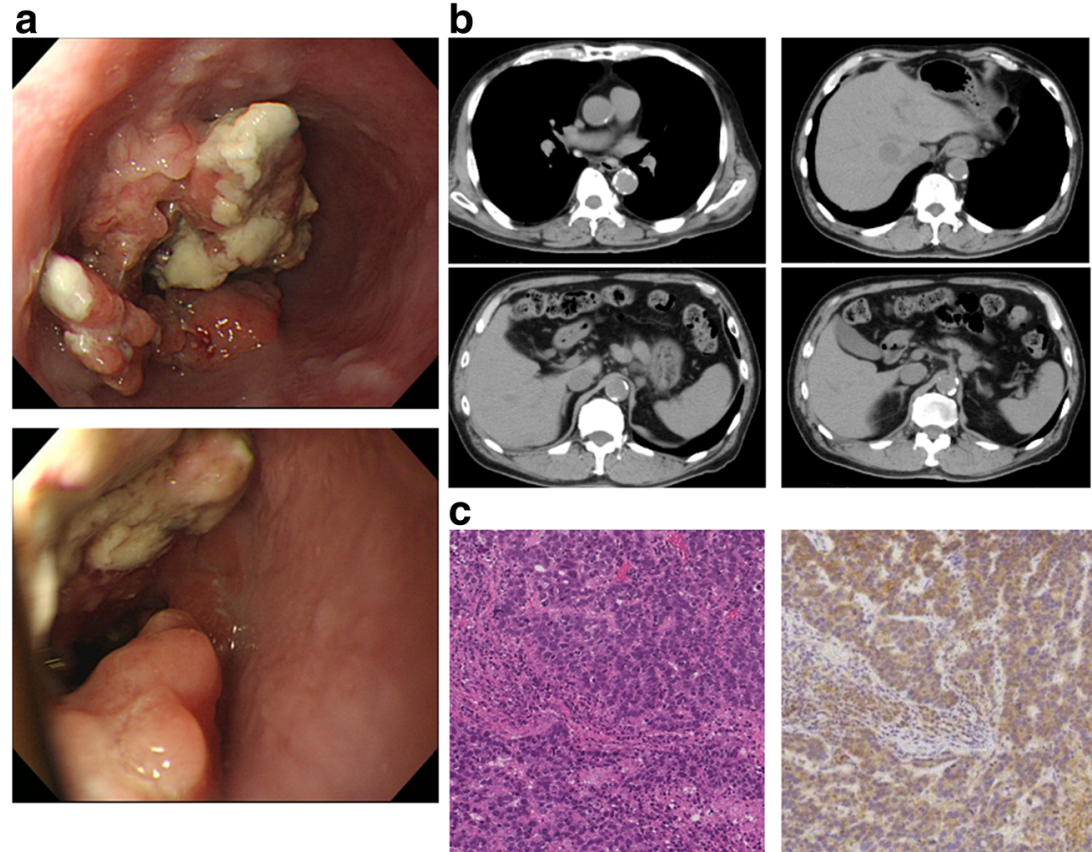

diamminedichloroplatinum (CDDP) therapy was recommended in the guidelines of the Japan Gastric Cancer Association, we hesitated to administer CDDP because of renal dysfunction due to diabetes. Therefore, S-1 + docetaxel (DOC) therapy was selected instead. Although grade 3 leukopenia and grade 2 anorexia and stomatitis were observed at the beginning of treatment, the therapy could be continued with a dose reduction. After 12 courses of chemotherapy, CT and contrastenhanced ultrasonography revealed that only one lesion remained (S4) in the liver and that there was no lymph node metastasis. Because the liver metastatic lesion was close to vessels, chemotherapy and percutaneous ethanol therapy
(PEIT) were selected in consideration of the patient's safety and invasiveness. Maintenance chemotherapy with S-1 was then administered for 10 months. Thereafter, the patient's serum AFP level decreased to the normal range. The patient has shown no recurrence in the 77 months since surgery (Fig. 2).

\section{Discussion}

We reported a rare case of an AFP-producing carcinoma of the esophagogastric junction, in which long-term survival was achieved through multidisciplinary therapy that included
Fig. 2 The changes in the CT findings during multidisciplinary therapy. a CT showed multiple metastases in the lymph nodes and liver. b After chemotherapy and percutaneous ethanol therapy (PEIT), all of the metastatic lesions disappeared
$\mathrm{S} 4$
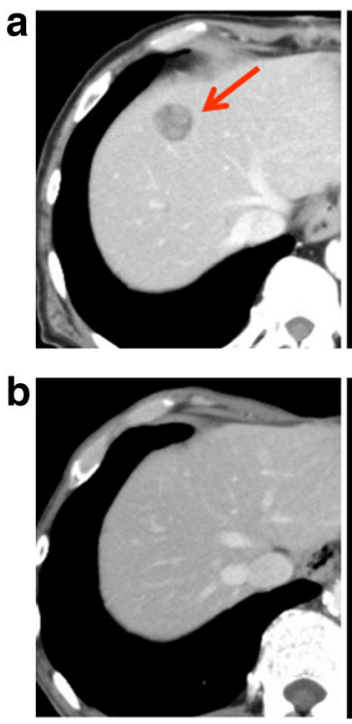

S8
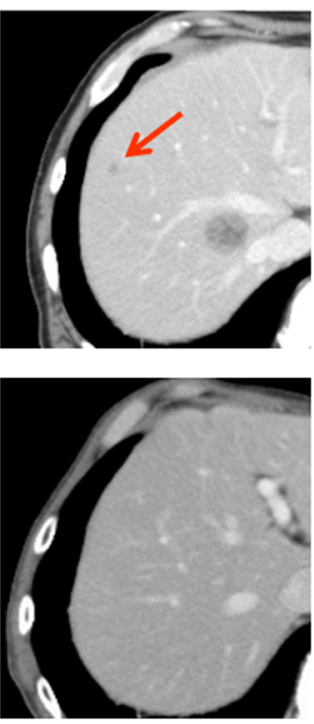

S6/7
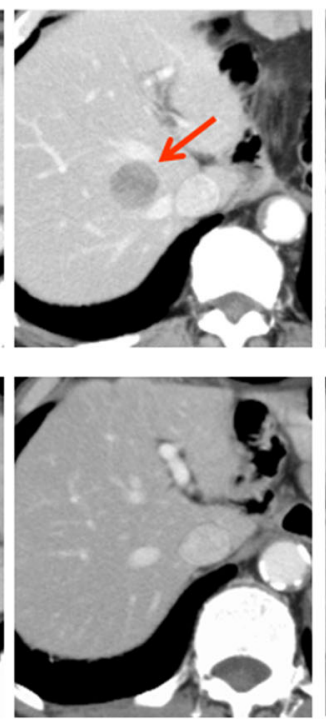

\#11p L/N
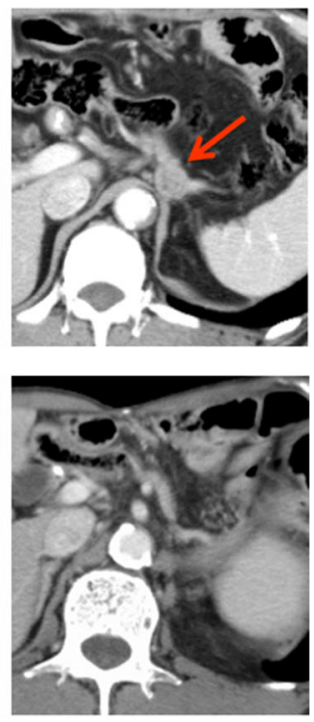


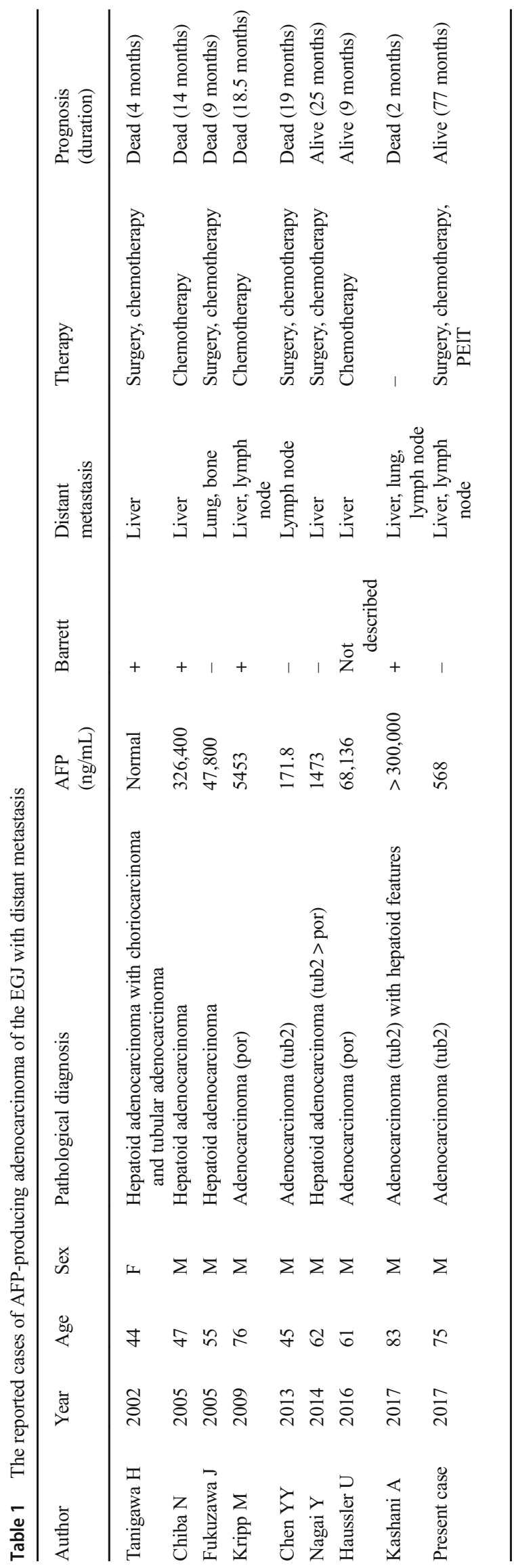

surgery, chemotherapy, and PEIT. AFP-producing carcinoma of the gastrointestinal tract is considered to have a high potential for liver metastasis [8-11]. Carcinoma of the esophagogastric junction, particularly in advanced stages, is also known to have high malignant potential and shows a poor prognosis $[1,2]$. It is notable that long-term survival was achieved in the present case despite the presence of two such unfavorable factors. The outcome suggests that our multidisciplinary approach is a practical option for the treatment tumors with such high malignant potential.

To date, eight cases exhibiting AFP-producing carcinomas of the EGJ have been reported in the literature (Table 1) [13-20]. Five cases were reported from Asia and three were reported from other regions. An association with Barrett's esophagus was reported in half of the cases $[13,14,16,20]$, but in others no relationship was found $[15,17-19]$. The histological subtypes were as follows: adenocarcinoma $(n=3)$ $[16,17,19]$, hepatoid adenocarcinoma $(n=3)[14,15,18]$, adenocarcinoma/hepatoid adenocarcinoma $(n=1)$ [20], and mixed-type $(n=1)$ [13]. There were no cases of squamous cell carcinoma. Distant metastasis was frequently detected in cases with high serum levels of AFP at the diagnosis [14-16, 18-20]. The serum level of AFP appears to be useful as a marker of metastasis [17]. With regard to the prognosis, the present case achieved the highest survival term. In the present case, various treatments, including surgery, chemotherapy, and PEIT, were combined according to the patient's condition because he had various complications, including renal failure and diabetes. PEIT is generally used for the treatment of hepatocellular carcinoma, while it is less commonly used for metastatic lesions from other organs, because most metastatic cases exhibit multiple lesions as well as frequent recurrences. However, the present case achieved the longest known survival period using PEIT, thus suggesting that personalized multidisciplinary therapy, including local treatments, such as PEIT, which are appropriate for the patient's condition, is essential for the treatment of tumors with such a high malignant potential. The further accumulation of similar cases will be useful for establishing an appropriate therapeutic strategy for AFP-producing carcinomas that develop at the EGJ.

Acknowledgments We would appreciate Dr. Takuya Iwama and Dr. Yuya Sugiyama for significant assistances.

Availability of Data and Materials All data analyzed during this study are included in this published article.

Authors' Contributions K.T. and M.F. contributed equally to this study. K.T. and M.F. conceived the report, collected data, and wrote the first draft of the report. K.T., M.I., T.I., and H.T. followed up the patient. K.T, K.A., and Y.N. performed endoscopy and evaluated the disease severity. S.K., T.G., and J.S. evaluated radiological images including the computed tomography scans. K.M., Y.M., and T.O. supervised the study. All authors contributed to the critical revision of the report for important intellectual content. 


\section{Compliance with Ethical Standards}

Ethics Approval and Consent to Participate This case report did not require the review by the Institutional Review Board of Asahikawa Medical University.

Consent for Publication Written informed consent was obtained from the patient for publication of the case report and any accompanying images.

Conflict of Interest The authors declare that they have no conflict of interest.

Abbreviations $A F P$, alpha-fetoprotein; $E G J$, esophagogastric junction; $C E A$, carcinoembryonic antigen; $S C C$, squamous cell carcinoma; $C A 19$ 9, carbohydrate 19-9 antigen; $C T$, computed tomography; $M R I$, magnetic resonance imaging; PEIT, percutaneous ethanol therapy

Open Access This article is distributed under the terms of the Creative Commons Attribution 4.0 International License (http:// creativecommons.org/licenses/by/4.0/), which permits unrestricted use, distribution, and reproduction in any medium, provided you give appropriate credit to the original author(s) and the source, provide a link to the Creative Commons license, and indicate if changes were made.

\section{References}

1. Siewert JR, Feith M, Stein HJ. Biologic and clinical variations of adenocarcinoma at the esophago-gastric junction: relevance of a topographic-anatomic subclassification. J Surg Oncol. 2005;90: 139-46. https://doi.org/10.1002/jso.20218.

2. Hasegawa S, Yoshikawa T. Adenocarcinoma of the esophagogastric junction: incidence, characteristics, and treatment strategies. Gastric Cancer. 2010;11:63-73. https://doi.org/10.1007/ s10120-010-0555-2.

3. Kurokawa Y, Hiki N, Yoshikawa T, Kishi K, Ito Y, Ohi M, et al. Mediastinal lymph node metastasis and recurrence in adenocarcinoma of the esophagogastric junction. Surgery. 2015;157:551-5. https://doi.org/10.1016/j.surg.2014.08.099.

4. Hulscher JB, van Sandick JW, de Boer AG, et al. Extended transthoracic resection compared with limited transhiatal resection for adenocarcinoma of the esophagus. N Engl J Med. 2002;347:16629. https://doi.org/10.1056/NEJMoa022343.

5. Kurokawa Y, Sasako M, Sano T, Yoshikawa T, Iwasaki Y, Nashimoto A, et al. Ten-year follow-up results of a randomized clinical trial comparing left thoracoabdominal and abdominal transhiatal approaches to total gastrectomy for adenocarcinoma of the oesophagogastric junction or gastric cardia. Br J Surg. 2015;102:341-8. https://doi.org/10.1002/bjs.9764.

6. Yoshikawa T, Takeuchi H, Hasegawa S, Nozaki I, Kishi K, Ito S, et al. Theoretical therapeutic impact of lymph node dissection on adenocarcinoma and squamous cell carcinoma of the esophagogastric junction. Gastric Cancer. 2016;19:143-9. https:// doi.org/10.1007/s10120-014-0439-y.
7. Gitlin D, Perricelli A, Gitlin GM. Synthesis of $\alpha$-fetprotein by liver, yolk sac, and gastrointestinal tract of human conceptus. Cancer Res. 1972;32:979-82.

8. Chang YC, Nagasue N, Kohno H, Taniura H, Uchida M, Yamanoi A, et al. Clinicopathologic features and long-term results of alphafetoprotein-producing gastric cancer. Am J Gastroenterol. 1990;85: 1480-5.

9. Chang YC, Nagasue N, Abe S, Taniura H, Kumar DD, Comparison NT. Between the clinicopathologic features of AFP-positive and AFP-negative gastric cancers. Am J Gastroenterol. 1992;87:321-5.

10. Adachi Y, Tsuchihashi J, Shiraishi N, Yasuda K, Etoh T, Kitano S. AFP-producing gastric carcinoma: multivariate analysis of prognostic factors in 270 patients. Oncology. 2003;65:95-101. https:// doi.org/10.1159/000072332.

11. Inoue M, Sano T, Kuchiba A, Taniguchi H, Fukagawa T, Katai H. Long-term results of gastrectomy for alpha-fetoprotein-producing gastric cancer. Br J Surg. 2010;97:1056-61. https://doi.org/10. 1002/bjs. 7081.

12. Nagai E, Ueyama T, Yao T, Tsuneyoshi M. Hepatoid adenocarcinoma of the stomach. A clinicopathologic and immunohistochemical analysis. Cancer. 1993;15(72):1827-35.

13. Tanigawa H, Kida Y, Kuwao S, Uesugi H, Ojima T, Kobayashi N, et al. Hepatoid adenocarcinoma in Barrett's esophagus associated with achalasia: first case report. Pathol Int. 2002;52:141-6.

14. Chiba N, Yoshioka T, Sakayori M, Mikami Y, Miyazaki S, Akiyama S, et al. AFP-producing hepatoid adenocarcinoma in association with Barrett's esophagus with multiple liver metastasis responding to paclitaxel/CDDP: a case report. Anticancer Res. 2005;25:2965-8.

15. Fukuzawa J, Terashima H, Nakano Y, Nakahashi C, Oda T, Yuzawa $\mathrm{K}$, et al. Alpha-fetoprotein producing adenocarcinoma of esophagogastric junction: a case report. Jpn J Gastroenterol Surg. 2005;38:401-5.

16. Kripp M, Ströbel P, Dinter D, Lukan N, Hochhaus A, Hofheinz RD. Alpha-fetoprotein expressing metastastic adenocarcinoma of the esophago-gastric junction responding favorably to capecitabine and oxaliplatin. Anti-Cancer Drugs. 2009;20:75-8. https://doi.org/ 10.1097/CAD.0b013e328312659a.

17. Chen YY, Hsu WH, Hu HM, Wu DC, Lin WY. A case of alphafetoprotein-producing esophageal adenocarcinoma. Kaohsiung J Med Sci. 2013;29:106-10. https://doi.org/10.1016/j.kjms.2012.08. 018.

18. Nagai Y, Kato T, Harano M, Satoh D, Choda Y, Tokumoto N, et al. A case of AFP-producing esophagogastric junction cancer with liver metastases with a good response to chemotherapy. Gan To Kagaku Ryoho. 2014;41:2349-51.

19. Häussler U, Bitzer M, Bösmüller H, Clasen S, Götz M, Malek N, et al. AFP-producing adenocarcinoma of the esophagogastric junction: report of a case with atypical immunohistochemical findings responding to palliative chemotherapy with 5 -fluorouracil, leucovorin, oxaliplatin, and docetaxel (FLOT regime). Z Gastroenterol. 2016;54:1147-50. https://doi.org/10.1055/s-0042114575.

20. Kashani A, Ellis JC, Kahn M, Jamil LH. Liver metastasis from hepatoid adenocarcinoma of the esophagus mimicking hepatocellular carcinoma. Gastroenterol Rep (Oxf). 2017;5:67-71. https:// doi.org/10.1093/gastro/gov021. 